\title{
Thermal stability of sputter-deposited 330 austenitic stainless-steel thin films with nanoscale growth twins
}

Cite as: Appl. Phys. Lett. 87, 233116 (2005); https://doi.org/10.1063/1.2135871

Submitted: 09 August 2005. Accepted: 14 October 2005. Published Online: 02 December 2005

X. Zhang, A. Misra, H. Wang, J. G. Swadener, A. L. Lima, M. F. Hundley, and R. G. Hoagland

ARTICLES YOU MAY BE INTERESTED IN

Thermal stability of sputtered Cu films with nanoscale growth twins

Journal of Applied Physics 103, 094322 (2008); https://doi.org/10.1063/1.2913322

High-strength sputter-deposited Cu foils with preferred orientation of nanoscale growth twins

Applied Physics Letters 88, 173116 (2006); https://doi.org/10.1063/1.2198482

Effects of deposition parameters on residual stresses, hardness and electrical resistivity of nanoscale twinned 330 stainless steel thin films

Journal of Applied Physics 97, 094302 (2005); https://doi.org/10.1063/1.1883724

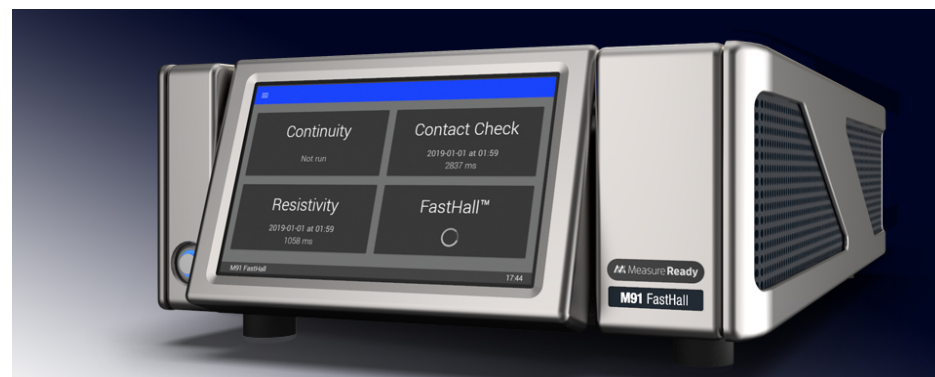

\section{No Measure Ready} M91 FastHall ${ }^{\mathrm{TM}}$ Controller

A revolutionary new instrument for complete Hall analysis 


\title{
Thermal stability of sputter-deposited 330 austenitic stainless-steel thin films with nanoscale growth twins
}

\author{
X. Zhang a) \\ Department of Mechanical Engineering, Texas A\&M University, College Station, Texas 77843-3123
}

\begin{abstract}
A. Misra, H. Wang, ${ }^{\text {b) }}$ J. G. Swadener, A. L. Lima, M. F. Hundley, and R. G. Hoagland
Materials Science and Technology Division, Los Alamos National Laboratory, Los Alamos, New Mexico 87545
\end{abstract}

(Received 9 August 2005; accepted 14 October 2005; published online 2 December 2005)

\begin{abstract}
We have explored the thermal stability of nanoscale growth twins in sputter-deposited 330 stainless-steel (SS) films by vacuum annealing up to $500{ }^{\circ} \mathrm{C}$. In spite of an average twin spacing of only $4 \mathrm{~nm}$ in the as-deposited films, no detectable variation in the twin spacing or orientation of twin interfaces was observed after annealing. An increase in the average columnar grain size was observed after annealing. The hardness of $330 \mathrm{SS}$ films increases after annealing, from $7 \mathrm{GPa}$ for as-deposited films to around $8 \mathrm{GPa}$ for annealed films, while the electrical resistivity decreases slightly after annealing. The changes in mechanical and electrical properties after annealing are interpreted in terms of the corresponding changes in the residual stress and microstructure of the films. (C) 2005 American Institute of Physics. [DOI: 10.1063/1.2135871]
\end{abstract}

We have recently synthesized single-phase 330 stainless steel (330 SS) thin films with a high density of growth twins, oriented parallel to the film surface. ${ }^{1}$ These twins are only $2-4 \mathrm{~nm}$ thick. Furthermore, the average spacing between adjacent twins was around $4 \mathrm{~nm}$. The strength of as-deposited 330 SS thin films is about an order of magnitude higher than that of bulk 330 SS. ${ }^{1}$ It was suggested that the twinned structures with average spacing of a few nanometers cause plasticity by the motion of single rather than pileups of dislocations. Furthermore, molecular dynamics simulations have shown that twin interface is a strong barrier to the transmission of single dislocation and the resistance to transmission depends sensitively on the stress state. ${ }^{1,2}$ These nanoscale growth twins have little impact on the increase of the resistivity of films ${ }^{2}$ and might therefore lead to a strategy for the synthesis of high strength and high conductivity materials. Such has recently been shown in electrodeposited $\mathrm{Cu}$ with nanoscale growth twins. ${ }^{3-5} \mathrm{~A}$ model based on thermodynamics and kinetics of nucleation was developed in our earlier work to account for the formation of nanoscale growth twins during physical vapor deposition in terms of twin boundary or stacking fault energy and deposition rate. ${ }^{6}$ The formation of growth twins is favored if deposited materials have low stacking fault energies or a high deposition rate is applied during growth.

In this letter, we attempt to explore the thermal stability of these nanoscale twins, as stability of twinned materials at a higher temperature is desirable for their high temperature applications.

330 SS thin films, about $1 \mu \mathrm{m}$ thick, were sputtered deposited onto oxidized Si substrates with about $200 \mathrm{~nm}$ thick $\mathrm{SiO}_{2}$ using similar conditions as reported before. ${ }^{1}$ All depositions were performed at room temperature. Annealing of 330 SS films was performed from $200{ }^{\circ} \mathrm{C}$ to $500{ }^{\circ} \mathrm{C}$, in a

\footnotetext{
${ }^{\text {a) }}$ Author to whom correspondence should be addressed; electronic mail: zhangx@tamu.edu

b) Address as of January 2006: Department of Electrical Engineering, Texas A\&M University, College Station, Texas 77843-3128.
}

custom-designed annealing furnace with a back pressure of less than $5 \times 10^{-7}$ Torr. High-resolution transmission electron microscopy (HRTEM) was performed on a JEOL 3000F microscope operated at $300 \mathrm{kV}$. The hardness and indentation modulus of multilayers were measured, at room by a commercial Nano XP Instrument, using a Berkovich indenter. Temperature-dependent (4 to $300 \mathrm{~K})$ electrical resistivity measurements were made with a low-frequency ac resistance bridge. A four-probe sample configuration was used, and Ohmic contacts were made with a silver conductive paint.

The as-deposited 330 SS film has an average columnar grain size of around $30 \mathrm{~nm}$ and $\{111\}$ fiber texture along growth direction. ${ }^{1}$ High-density planar defects (mostly growth twins as revealed by HRTEM) are observed with the columnar grains. The average twin spacing of as-deposited

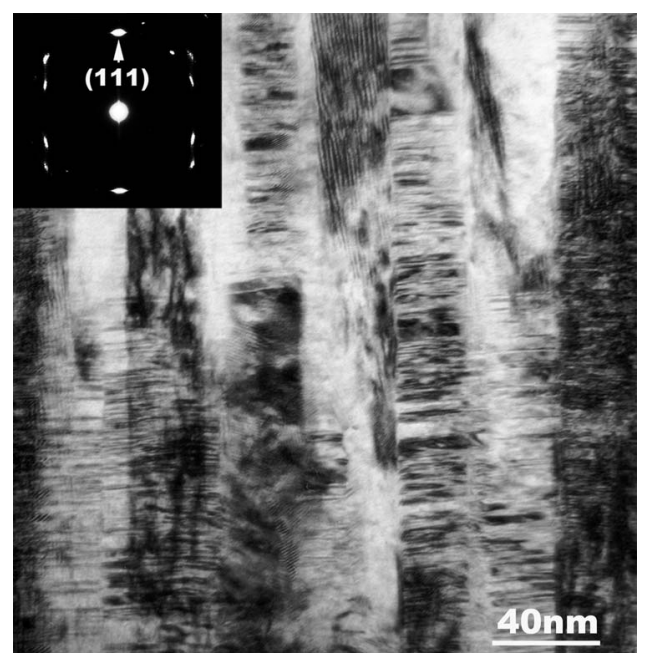

FIG. 1. Cross-sectional TEM micrograph of $330 \mathrm{SS}$ films annealed at $400{ }^{\circ} \mathrm{C}$ for $1 \mathrm{~h}$. The film has a similar microstructure, $\{111\}$ fiber texture, high-density nanoscale growth twins oriented parallel to the film surface, to that of as-deposited films. A slight increase of the average columnar grain size is observed. 

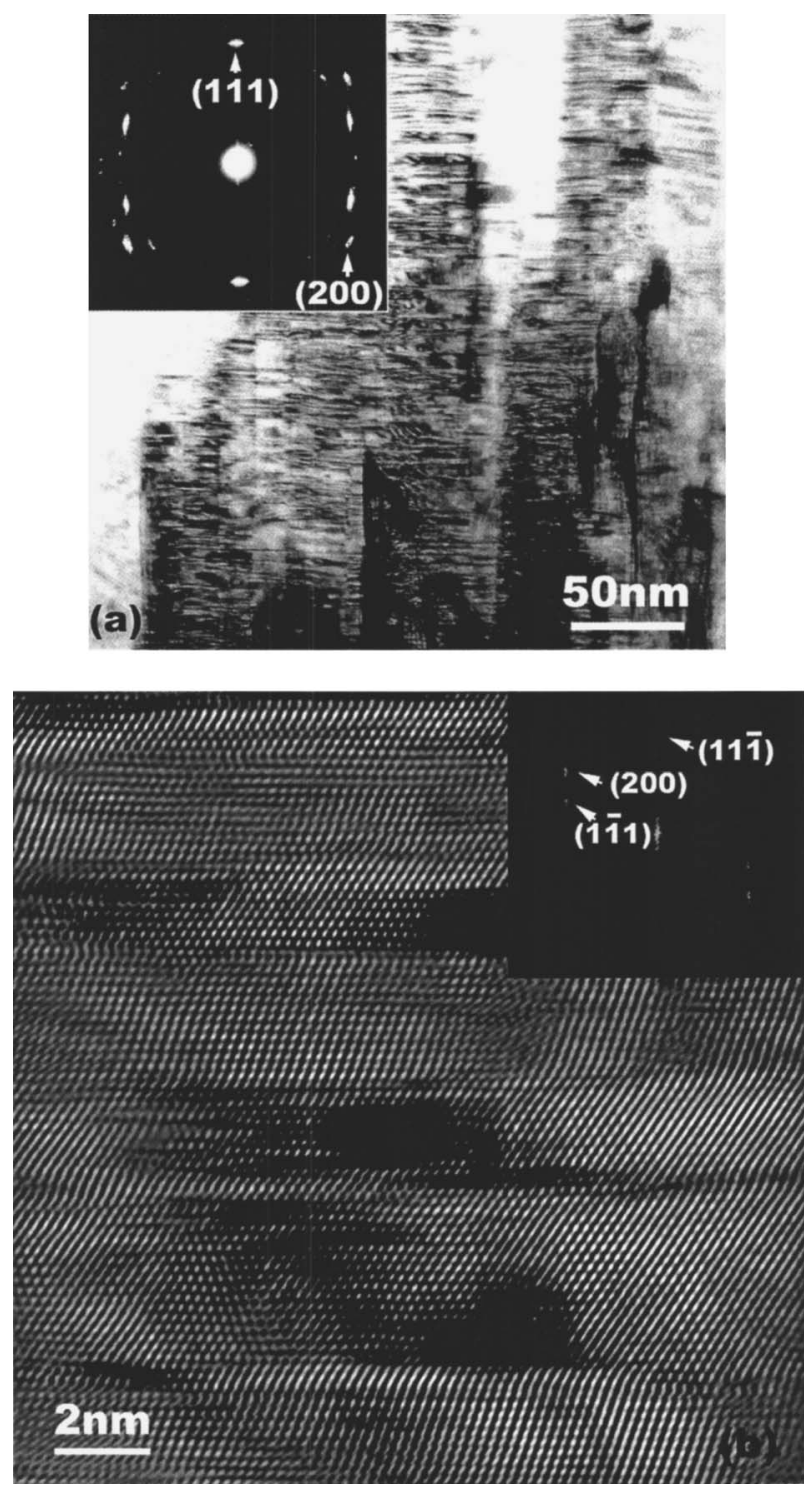

FIG. 2. (a) Cross-sectional TEM micrograph of $330 \mathrm{SS}$ films annealed at $500{ }^{\circ} \mathrm{C}$ for $1 \mathrm{~h}$. (b) Cross-sectional HRTEM micrograph and the inserted fast Fourier transform of the same film show the configuration of twins are almost identical to that of as-deposited films. The average columnar grain size increases from $30 \mathrm{~nm}$ for as-deposited films to $40 \mathrm{~nm}$ after annealing.

330 SS films is calculated to be around $4-5 \mathrm{~nm}$ from many measurements. ${ }^{1}$ Compared with as-deposited ones, 330 SS films annealed at $400{ }^{\circ} \mathrm{C}$ possess similar microstructures, as presented in Fig. 1. Specifically, films annealed at $400{ }^{\circ} \mathrm{C}$ possess a similar $\{111\}$ fiber texture along growth direction, and nanoscale growth twins oriented parallel to the films surfaces separated by a few nm twin spacing. A slight increase of the average columnar grain sizes has been observed. The high density growth twins and $\{111\}$ texture in the films remain even after annealing at $500{ }^{\circ} \mathrm{C}$ as shown in Fig. 2(a). An increase in the average columnar grain sizes, from $30 \mathrm{~nm}$ to around $40 \mathrm{~nm}$, is observed. Cross-sectional HRTEM micrograph, given in Fig. 2(b), reveals a typical $\{111\}$-type twin interface parallel to the film surface, as indicated by the inserted fast Fourier transform of the image. The average twin spacing of $330 \mathrm{SS}$ films annealed at $500{ }^{\circ} \mathrm{C}$, measured from transmission electron microscopy (TEM) images, is almost the same as that in as-deposited films.

As-deposited 330 SS films possess a residual compressive growth stress, on the order of $\sim 200 \mathrm{MPa}^{2}$ Evolution of

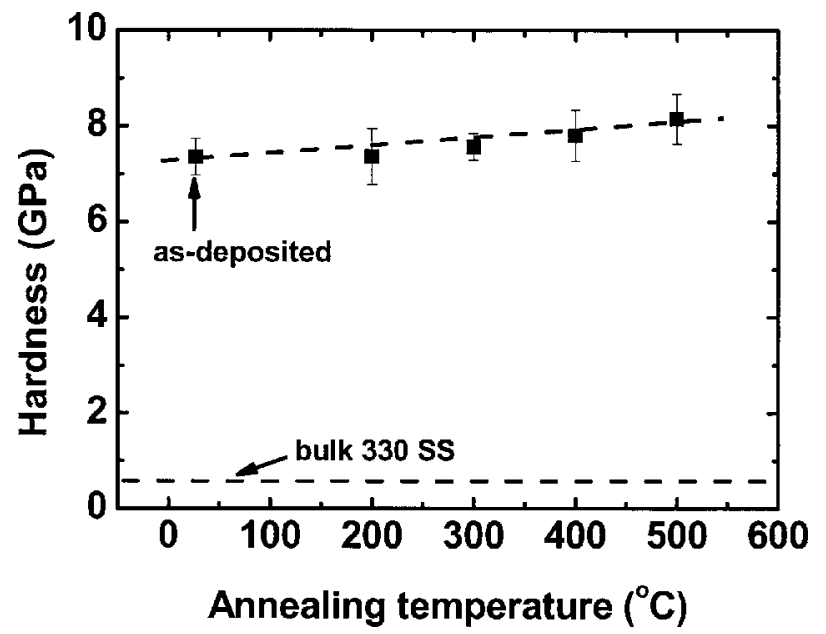

FIG. 3. Evolution of the hardness of 330 SS films, measured by nanoindentation, with annealing temperature. A slight increase in hardness is observed after annealing to $500{ }^{\circ} \mathrm{C}$. The horizontal dashed line indicates the hardness of annealed bulk 330 SS.

film hardness, determined from nanoindentation experiments, with annealing temperature is plotted in Fig. 3. Hardness of the films increases slightly from $7 \mathrm{GPa}$ for asdeposited condition to around $8 \mathrm{GPa}$ for samples annealed at $500{ }^{\circ} \mathrm{C}$. In all cases, the hardness of $330 \mathrm{SS}$ films are about an order of magnitude higher than that of bulk $330 \mathrm{SS}$ which is about $0.6 \mathrm{GPa},{ }^{7,8}$ as indicated by the dashed line in Fig. 3 . Annealing at a higher temperature $\left(600^{\circ} \mathrm{C}\right)$ led to the delamination of films and, therefore, no hardness data could be obtained.

After annealing, the electrical resistivity of 330 SS films, measured at room temperature, decreases gradually by a small amount from $110 \mu \Omega \mathrm{cm}$ for as-deposited specimens to $106 \mu \Omega \mathrm{cm}$ for the samples annealed at $500{ }^{\circ} \mathrm{C}$ as shown in Fig. 4. The resistivity of annealed bulk 330 SS is around $102 \mu \Omega \mathrm{cm}$ as shown by the dashed line on the plot. ${ }^{7,8}$

The nanoscale growth twins in 330 SS films show remarkable thermal stability. Even at temperatures as high as $500{ }^{\circ} \mathrm{C}\left(\approx 0.46 T_{m}\right.$, where $T_{m}$ is the melting point of $330 \mathrm{SS}$ in degrees Kelvin), no significant coarsening of the nanoscale twinned structure was discerned in TEM images, except for a modest increase in the average columnar grain sizes, from $30 \mathrm{~nm}$ to around $40 \mathrm{~nm}$. The grain boundary energy of bulk SS is typically on the order of $1 \mathrm{~J} / \mathrm{m}^{2}$, whereas the twin boundary energy of $330 \mathrm{SS}$ is two orders of magnitude smaller, $\sim 10 \mathrm{~mJ} / \mathrm{m}^{2}{ }^{9}$. Assume a surface area of $1 \mathrm{~m}^{2}$, the total grain boundary energy stored within $1 \mu \mathrm{m}$ thick films is around $18 \mathrm{~J}$, whereas the total twin boundary energy stored is approximately one order of magnitude smaller, around $2 \mathrm{~J}$. The driving force for reducing the total grain boundary energy of the system via grain coarsening is obviously higher than that for the reduction of twin boundary energy. This estimation is consistent with experimental observations that twin boundaries of 330 SS remains unchanged whereas the grain size is enlarged by $30 \%$ after annealing at $500{ }^{\circ} \mathrm{C}$.

In metallic systems with nanocrystalline grain sizes, annealing typically results in a drop in hardness due to grain growth. For annealed $330 \mathrm{SS}$ films, however, the increase of columnar grain sizes by $\approx 30 \%$ after annealing at $500{ }^{\circ} \mathrm{C}$ did not lead to any reduction of the film hardness, in fact a slight increase in the measured hardness was observed. This is because the columnar grain sizes are much larger than the av- 


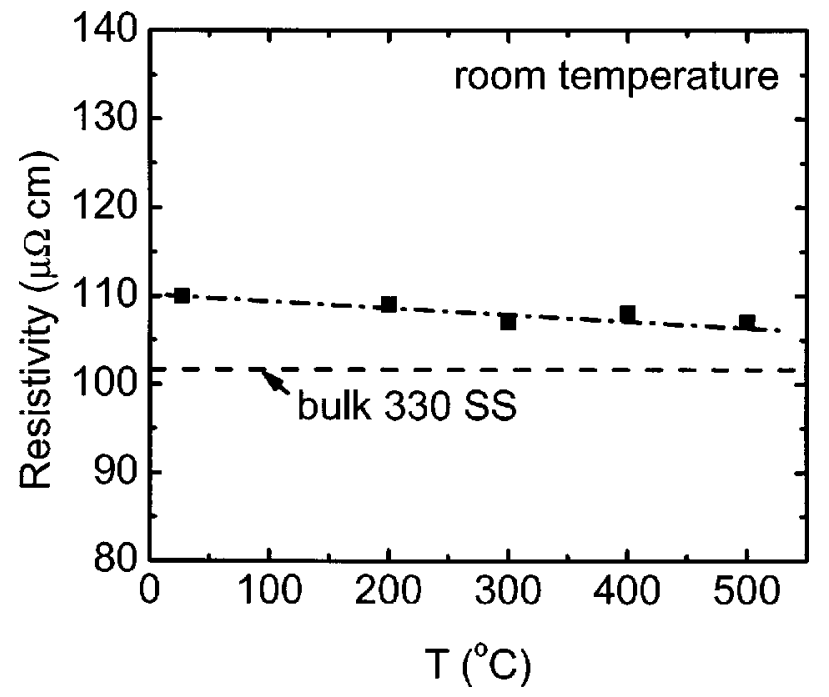

FIG. 4. Evolution of the electrical resistivity of 330 SS films with annealing temperature. A slight decrease in the electrical resistivity is observed after annealing.

erage twin spacing in $330 \mathrm{SS}$ films and have little influence on the strength of 330 SS films, as slip is confined by the smaller length scales, i.e., twin interface separated by a few $\mathrm{nm}$.

The slight increase of the measured hardness during annealing could be a result of the evolution of film stresses. It is known that hardness typically decreases with tensile stress and increases with compressive stress, and the effects of compression are often not as large as the tension. ${ }^{10,11}$ Details for the explanation of these phenomena can be found in Refs. 12 and 13. The influence of residual stress on material hardness has been used to estimate residual stress through hardness measurement techniques. ${ }^{14-16}$ The as-deposited 330 SS films possess a compressive growth stress of $\sim 200 \mathrm{MPa}$. During annealing, an even more compressive residual stress could be developed due to a large thermal expansion coefficient difference, $\Delta \alpha$, between $330 \mathrm{SS}$ films and Si substrate. The variation of stress with annealing temperature could be described as: ${ }^{11}$

$$
\frac{d \sigma}{d T}=\left(\frac{E}{1-\nu}\right)_{\text {film }} \Delta \alpha
$$

where $\Delta \alpha$ is the difference in thermal expansion coefficients for the film and substrate. $E$ and $\nu$ are Young's modulus and Poisson's ratio of the film. Given $E$ and $\nu$ are $200 \mathrm{GPa}$ and 0.29 for 330 SS films, a compressive stress of around 100-300 MPa will be developed during annealing due to the difference in thermal expansion coefficients of 330 SS films and Si substrate. We suspect that the increase of compressive stress in films after annealing could lead to the higher measured hardness.

The electrical resistivity of as-deposited $330 \mathrm{SS}$ films is higher than that of annealed bulk 330 SS. Using the model proposed by Mayadas and Shatzkes, ${ }^{17}$ we have calculated the increase of resistivity due to grain boundary scattering. The calculation shows the increase of resistivity in 330 SS may be attributed mainly to grain boundary scattering. ${ }^{2}$ The electron scattering at twin boundaries is known to influence the resistivity by an order of magnitude less than does scattering at grain boundaries. ${ }^{18}$ As such, the high density of nanoscale twins will have little effect on the resistivity of 330 SS films. The increases of average columnar grain size from $30 \mathrm{~nm}$ to $40 \mathrm{~nm}$ after annealing at $500{ }^{\circ} \mathrm{C}$ will lead to a decrease in resistivity from $110 \mu \Omega \mathrm{cm}$ to $107 \mu \Omega \mathrm{cm}$. Therefore, the reduction of electrical resistivity after annealing should be a result of grain coarsening.

Nanoscale twin structures in sputter-deposited 330 SS films have shown considerable thermal stability, i.e., the configurations of twins, especially average twin spacing and orientation of twin interface remain unchanged after annealing up to $500{ }^{\circ} \mathrm{C}$. An increase in the columnar grain size was observed in annealed $330 \mathrm{SS}$ films that leads to a reduction in electrical resistivity. The hardness of films shows no reduction with grain coarsening as the strength of these films with nanoscale twins is primarily controlled by the critical resolved shear stress to transmit a single dislocation across twin interfaces, with only a secondary contribution from the relatively much larger column grain size.

This research was funded by DOE, Office of Science, Office of Basic Energy Sciences. One of the authors (X.Z.) acknowledges financial support from DOE-NERI, Office of Nuclear Energy, Science and Technology, AFCI program, under Grant No. DE-FC07-05ID14657 with Dr. Michael Cappiello as the program manager. Discussions with J. P. Hirth, J. D. Embury, M. Nastasi, and T. E. Mitchell are gratefully appreciated.

${ }^{1}$ X. Zhang, A. Misra, H. Wang, M. Nastasi, J. D. Embury, T. E. Mitchell, R. G. Hoagland, and J. P. Hirth, Appl. Phys. Lett. 84, 1096 (2004).

${ }^{2}$ X. Zhang, A. Misra, H. Wang, A. L. Lima, M. F. Hundley, and R. G. Hoagland, J. Appl. Phys. 97, 094302 (2005).

${ }^{3}$ L. Lu, Y. Shen, X. Chen, L. Qian, and K. Lu, Science 304, 422 (2004).

${ }^{4}$ Y. F. Shen, L. Lu, Q. H. Lu, Z. H. Jin, and K. Lu, Scr. Mater. 52, 989 (2005).

${ }^{5}$ E. Ma, Y. M. Wang, Q. H. Lu, M. L. Sui, L. Lu, and K. Lu, Appl. Phys. Lett. 85, 4932 (2004).

${ }^{6}$ X. Zhang, A. Misra, H. Wang, T. D. Shen, M. Nastasi, T. E. Mitchell, J. P. Hirth, R. G. Hoagland, and J. D. Embury, Acta Mater. 52, 995 (2004).

${ }^{7}$ Engineering Properties of Steels, edited by P. D. Harvey (American Society for Metals, Metals Park, OH, 1982).

${ }^{8}$ Metals Handbook, edited by H. E. Boyer and T. L. Gall (American Society for Metals, Materials Park, OH, 1985).

${ }^{9}$ C. G. Rhodes and A. W. Thompson, Metall. Trans. A 8A, 1901 (1977).

${ }^{10} \mathrm{H}$. Kostron, Metallwirtschaft 12, 473 (1933).

${ }^{11}$ M. F. Doerner, D. S. Gardner, and W. D. Nix, J. Mater. Res. 1, 845 (1986).

${ }^{12}$ G. Sines and R. Carlson, Am. Soc. Testing Mater. Bull. 180, 35 (1952).

${ }^{13}$ T. Y. Tsui, W. C. Oliver, and G. M. Pharr, J. Mater. Res. 11, 752 (1996).

${ }^{14}$ J. G. Swadener, B. Taljat, and G. M. Pharr, J. Mater. Res. 16, 2091 (2001).

${ }^{15}$ A. E. Giannakopoulos, J. Appl. Mech. 70, 638 (2003).

${ }^{16}$ S. Suresh and A. E. Giannakopoulos, Acta Mater. 46, 5755 (1998).

${ }^{17}$ A. F. Mayadas and M. Shatzkes, Phys. Rev. B 1, 1382 (1970).

${ }^{18}$ A. P. Sutton and R. W. Balluffi, Interfaces in Crystalline Materials (Clarendon, Oxford, 1995). 